\title{
Primeiro contato do discente com a clínica: relato de experiência
}

\author{
Janaína Taiza Araújo de Jesus*, Jayane Andrade Santos*, Mayra da Paixão Conceição*, Thaís Reis Silva*, \\ Nathalie Oliveira Gonçalves**, Sérgio Donha Yarid***
}

\footnotetext{
* Graduandos em Odontologia na Universidade Estadual do Sudoeste da Bahia

** Mestranda no Programa de Pós-Graduação em Enfermagem e Saúde na Universidade Estadual do Sudoeste da Bahia

*** Professor Adjunto da Universidade Estadual do Sudoeste da Bahia
}

\begin{abstract}
RESUMO
A tarefa de formar profissionais tem parcelas de responsabilidade dos docentes, da instituição e do aluno, uma vez que o aprendizado propicia a capacidade de aprender, de se relacionar, trabalhar em equipe, comunicar-se e desenvolver as atividades de forma ética. Diante disso o presente estudo tem como objetivo conhecer e compreender as expectativas do discente do curso de Odontologia em seu primeiro contato com a clínica escola. Trata-se de um relato de caso, de caráter descritivo, exploratório, tendo como instrumento de coleta de dados a entrevista baseada em um roteiro e como participante, um estudante do $4^{\circ}$ semestre de Odontologia. A partir do relato do discente, foi possível agrupar o relato em três momentos, desde os anseios e expectativas, as dificuldades e facilidades na prática clínica e o conhecimento teórico e prático aplicado à prática clínica. Dessa forma observou-se que o discente de Odontologia em seu primeiro contato com a clínica escola apresenta uma mistura de expectativas em realizar atendimentos, com ansiedade e insegurança pela falta de experiência prática com o paciente, ao mesmo tempo em que se depara com pouco conhecimento teórico, uma vez que ainda se encontra na sua primeira prática clínica.
\end{abstract}

Descritores: Odontologia. Estudantes de Odontologia. Escolas de Odontologia. 


\section{INTRODUÇÃO}

A universidade tem o papel de formação profissional, onde se almeja formar um sujeito crítico, reflexivo e com formação ética. Dessa forma, as instituições usam técnicas pedagógicas de ensino-aprendizagem comprometidas com o desenvolvimento de valores humanizadores, para que o discente em formação pense, aja e reaja às situações na prática clínica de forma ética ${ }^{1}$.

Durante muitos anos a formação profissional em Odontologia ignorou práticas pedagógicas baseadas na problematização do ensino e na construção da aprendizagem coletiva, com isso o ensino se baseava na transferência bancária, onde os conhecimentos técnicos científicos eram depositados no aluno sem a associação com a realidade. Logo, era separado do contexto social e da realidade dos alunos e dos pacientes, e por ter um caráter considerado elitizado, estava disponível a uma menor parcela da população ${ }^{2}$.

Nesse contexto, se tratando de uma estratégia educacional da Odontologia é de relevância destacar a necessidade da prática, aliada ao ensino teórico durante o processo de formação profissional. Tratando-se da formação em Odontologia, o aluno passa a ter um papel de extrema responsabilidade na construção do seu conhecimento, colocando-o em pratica na clínica odontológica. Nesse sentido requer o desenvolvimento de senso crítico e reflexivo, sobre as tomadas de decisões no ambiente clinico ${ }^{3}$.

Dessa forma, é necessário que ocorra a real transformação do ensino na graduação, desde as matrizes curriculares até inovações nos cenários de ensino e aprendizagem. Com isso, a qualidade do ensino da Odontologia se relaciona a um adequado modelo pedagógico que se bem elaborado, traga uma abordagem completa e eficaz para a boa formação profissional ${ }^{4}$.

Diante disso, com o objetivo de melhorar a formação em Odontologia para os graduandos ainda na universidade, as Diretrizes Curriculares Nacionais (DCN), vigentes desde 2002, trazem o foco para a formação profissional de forma holística, para formar um profissional que ao mes- mo tenha uma visão do ser humano de forma completa, que seja crítico, reflexivo e ético, e que também tenha conhecimento técnico ${ }^{5}$.

Nesse contexto, para que exista a formação ética e de qualidade do graduando em Odontologia, as atividades práticas em clinicas integradas são fundamentais, pois fornecem ao aluno o exercício de averiguar sua formação e o vínculo estabelecido com o paciente, permitindo também avaliar seus conhecimentos em ambiente prático, com descoberta ou melhoria da destreza manual e habilidade motora, simulando a prática profissional e, consequentemente, adaptando-se para a futura vida profissional ${ }^{6}$.

No que se refere à formação universitária, observada a partir do processo educativo, científico e cultural, tem-se que o sucesso da relação entre o ensino e a prática está baseado na atenção à saúde que é prestada aos pacientes e se relaciona aos valores, conhecimentos e expectativas dos estudantes, para que a partir daí exista uma relação transformadora entre universidade e sociedade ${ }^{7}$.

Com isso é importante identificar e compreender o conhecimento e visão que os futuros profissionais que irão exercer a Odontologia possuem acerca dos problemas, frustações, anseios que são vivenciados nas clínicas escola dos cursos de Odontologia, para que assim seja possível conhecer as causas e a forma como eles vivenciam e superam essas questões.

\section{RELATO DE EXPERIÊNCIA}

Trata-se de um relato de experiência de caráter descritivo, e exploratório, tendo como cenário de pesquisa a clínica escola do curso de Odontologia da Universidade Estadual do Sudoeste da Bahia, campus de Jequié, Bahia.

$\mathrm{O}$ estudo foi realizado com graduandos do curso de Odontologia que estão no quarto semestre, por representar o momento em que se dá o primeiro contato do estudante com a clínica escola de Odontologia, e acontece durante a disciplina de Diagnóstico Oral, onde o mesmo de- 
senvolve a prática em um dia da semana, permanecendo nas atividades por dois horários. A disciplina tem um total de 24 alunos, que atuam em duplas durante a prática, e atendem a doze pacientes. Sendo assim, cada dupla é responsável pelo atendimento de um paciente sob supervisão do professor. Os procedimentos realizados são de exame clínico, profilaxia, radiografias, preenchimento do prontuário e elaboração do plano de tratamento.

A escolha do participante do estudo foi realizada de forma aleatória, onde se selecionou um discente, tendo como critério de inclusão ser aluno do quarto semestre de Odontologia, por se referir ao primeiro contato do discente com a clínica escola de odontologia.

A entrevista aconteceu em um encontro com duração de aproximadamente uma hora, na clínica escola, no momento de término das atividades práticas, da disciplina Pré-Clínica I, no mês de março de 2016.

Foi utilizado um roteiro para direcionar o entrevistador no momento da entrevista, onde as informações adquiridas pelo participante foram gravadas, transcritas e posteriormente analisadas de forma agrupada para melhor compreensão.

A pesquisa faz parte de um projeto intitulado Prontuário Odontológico sob a ótica dos docentes e discentes de Odontologia, aprovado pelo Comitê de Ética e Pesquisa da Universidade Estadual do Sudoeste da Bahia sob o número de parecer 247.926. Foram garantidos todos os aspectos éticos de pesquisa com seres humanos. A coleta de dados teve início após a assinatura do Termo de Consentimento Livre e Esclarecido assinado pelo participante da pesquisa.

O relato teve o intuito de descrever todas as expectativas vivenciadas pelo aluno durante seu primeiro contato com a prática e a realidade da profissão de cirurgião-dentista (CD), no momento em que o mesmo vai além do ambiente de sala de aula para adentrar a realidade prática, sendo o contato com os pacientes, momento em que vivenciam os anseios, medos e inseguranças, aliados à vontade de colocar em prática o conheci- mento teórico de que dispõem.

A análise do relato foi realizada a partir dos itens norteadores e dividida em três momentos, que abrangem desde as expectativas e anseios do graduando em odontologia; dificuldades e facilidades da prática clínica; conhecimento teórico e prático aplicado na clínica escola.

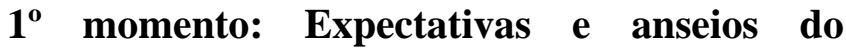 graduando em Odontologia}

O saber técnico-cientifico associado à prática clínica é de grande importância para o processo de formação profissional nos cursos da área da saúde, pois favorece o desempenho das habilidades do aluno no desenvolvimento dos procedimentos, permite uma melhor compreensão da realidade e reflexões acerca das condutas que devem ser realizadas de forma ética e humanizada. Com isso a realização das atividades em campo prático é ideal para o processo educacional, por ser o local onde estão sendo formados os futuros profissionais que serão responsáveis pelo cuidado e a atenção em saúde ${ }^{8}$.

Nesse contexto, durante o relato, alguns pontos serviram como norteadores para $\mathrm{o}$ direcionamento da entrevista, tais como, quais eram as expectativas em relação à clínica escola de Odontologia, antes de começar as práticas em clínica, e foi possível perceber através da fala do aluno que: "tinha expectativa de que eu atenderia uma gama maior de pacientes e de vamos dizer assim, de doenças, não que fosse tão restrito sabe? Então eu acho que eu tinha uma expectativa de que a prática seria mais intensa do que de fato é (...) um paciente só por turno, então isso diminui a quantidade de casos que a gente pega, essas coisas assim".

A possibilidade de contextualizar o conhecimento teórico com a prática e exercer todo o aprendizado obtido na sala de aula é a expectativa do aluno, momento em que é possível observar e aprender de perto sobre as doenças para assim desenvolver a segurança a fim de enriquecer as habilidades profissionais. Dessa forma, fica evidente no discurso do estudante de Odontologia 
a limitação dentro do contexto vivenciado, onde o mesmo se vê com insuficiência de experiências, para o aprimoramento do conhecimento que possui ${ }^{9}$.

No entanto, a preocupação do graduando não é a mesma que a do docente, pois este visa que o aluno, ao chegar à clínica escola, deve realizar atendimentos em níveis crescentes de complexidade, e que o paciente necessite de um tratamento específico e compatível com a habilidade do semestre determinado. Assim, além de se preocupar com a qualidade do atendimento, o docente deve acompanhar de perto a questão do aprendizado prático e o fluxo de pacientes para cada aluno, usando como base a falta inicial de habilidades suficientes para um atendimento rápido e cuidadoso, determinando a quantidade de pacientes $^{10}$.

Desse modo, fica ainda mais nítida a ansiedade do discente em adquirir habilidades práticas, sem perceber que de tal maneira estará rompendo todo um processo pedagógico estabelecido.

\section{$2^{\circ}$ momento: Dificuldades e facilidades da prática clínica}

Dentre os recursos utilizados como norteadores para o relato foi trazida a referência das dificuldades internas, onde se vê que “... deveria ter o mínimo de material pra que a gente pudesse utilizar, até porque quando a gente presta o vestibular a gente não imagina que a gente vai ter que comprar coisas, como por exemplo, luva, máscara, que são equipamentos de proteção individual e que em tese a faculdade deveria oferecer."

Neste contexto, percebe-se a importância dos momentos de prática, de realidade como etapa do processo de ensino aprendizagem, onde, contribui para que o aluno possa desenvolver atividades relacionadas à sua formação e, ainda, confronte com dilemas e conflitos que envolvem o processo de adoecimento e tratamento para que assim percebam suas inseguranças, medos e deficiências nos processos de trabalho ${ }^{11}$.
Assim, a falta de materiais na clínica escola inviabiliza a realização de determinados procedimentos na prática, o que dificulta a aprendizagem do aluno, uma vez que sem os materiais necessários não consegue realizar os procedimentos em disciplinas obrigatórias do curso. Com isso é certificado aos CD que não deve ser realizado procedimento em uma instituição de saúde que não proporcione as condições básicas para trabalho ou que ofereçam qualquer risco à saúde do seu paciente ${ }^{12}$.

Tratando- se de uma situação de urgência, fica explícito no estudo a insegurança por parte do aluno para realizar determinado procedimento necessário, alegando a falta de embasamento teórico e prático, estando ainda no quarto semestre. "Não. Eu não me sinto segura o suficiente pra fazer um procedimento de urgência. Eu acho que a gente ainda precisa passar por outras disciplinas que vão dar embasamento maior e por mais práticas porque as práticas que nós tivemos graças a Deus foram muito tranquilas ... então se eu tivesse que passar por uma situação de urgência sozinha, eu não saberia como proceder."

Com isso pode-se inferir que o CD é, antes de tudo, um profissional de saúde, que tem como principal objetivo a promoção da saúde, e diminuição dos riscos aos pacientes. Por isso deve ser formado com o intuito de deparar- se com várias situações, quer sejam especificas ou generalistas, de emergência e urgência ${ }^{13}$.

No que diz respeito ao primeiro atendimento do estudante de Odontologia na clínica escola, é notório que o fato de ser em uma disciplina como Diagnóstico Oral, que tem como objetivo ensinar ao aluno diagnosticar diversas patologias, além de oferecer a oportunidade de criação do vínculo com o paciente, não oferece procedimentos invasivos como cirurgias, fazendo com que o aluno esteja mais seguro para realizar o procedimento.

Apesar dos trabalhos manuais em clinicas e em laboratórios, que são fundamentais para aprimorar as habilidades dos alunos, o que estabelece maior segurança a eles, é também essencial para melhor desenvolvimento afetivo, 
sendo fundamental para criação do vínculo com o paciente, professores e colegas, mantendo maior controle emocional em situações de risco. É fundamental a organização de uma estrutura pedagógica em que os discentes cheguem à clínica escola com maior aprendizado na área de urgências e emergências, sentindo-se seguros para realizar qualquer técnica nesse tipo de situação ${ }^{13}$.

$\mathrm{Na}$ temática que norteou a entrevista com relação ao atendimento ao primeiro paciente, o aluno relatou que "senti muito bem, eu lembro do paciente, foi um rapaz que eu atendi, eu me senti segura, porque foi em Diagnóstico Oral, então é uma disciplina aparentemente tranquila porque a gente tem um suporte maior dos professores, e os procedimentos não são invasivos... eu me senti preparada para o primeiro atendimento".

A forma como o aluno aborda o paciente é fundamental para o procedimento, a formação humanística contribui para o estabelecimento de relação de confiança entre ambos, o que de fato contribui para procedimentos mais tranquilos, tanto para o paciente quanto para o discente ${ }^{14}$.

Nesse contexto, o conhecimento que o aluno possui passa a ser reconstruído a partir da soma do teórico com a realidade, constituindo-se de experiências vivenciadas e apreendidas ao longo da formação profissional. Assim, o mesmo passa a desempenhar um papel mais ético, reflexivo e responsável na construção do conhecimento, uma vez que ele entende que o aprendizado adentra a realidade trazida pelo paciente e o contexto que ambos vivenciam, e isto exige dele o desenvolvimento de senso crítico e reflexivo ${ }^{15}$.

Desse modo, o futuro CD deve refletir sobre seu comportamento e sua conduta para não demonstrar insegurança ao paciente. É de grande importância a criação de estratégias psicológicas para amenizar o medo do paciente, que, consequentemente, terá comportamentos mais colaborativos $^{14}$.

\section{$3^{\circ}$ momento: Conhecimento teórico e prático aplicado na clínica escola}

A parcela do estudo que diz respeito à inse- gurança do discente de Odontologia, abrange a necessidade de avaliações de casos clínicos mais complexos, notando que no atendimento clínico nem sempre apresentam condições ideais para o aprendizado dos alunos ${ }^{16}$. "Existem pessoas que tem um embasamento teórico enorme, mas não tem experiência e por isso ficam inseguras (...) eu particularmente acredito que a prática é que vai levar à experiência, então a prática é o que torna o estudante seguro...".

Apesar da preocupação em formar profissionais seguros e capacitados no período da graduação, o aprendizado e treinamento dos CDs são estabelecidos diariamente em seu consultório, sem a supervisão do docente ${ }^{16}$.

A necessidade de humanizar as práticas pedagógicas, deixando de lado o tecnicismo, a preocupação quanto aos processos educativos de forma social é fundamental na formação do CD, pois este se depara com uma realidade socioeconômica em que se devem priorizar as políticas públicas de saúde, visando o bem estar total do paciente ${ }^{17}$. “... especificamente pra mim que quero atuar nessa área de saúde coletiva, em que muito provavelmente, o público vai ser muito parecido, eu acho que é bem parte da minha realidade, é o nível de pessoas com o qual eu quero lidar e eu atendo hoje da maneira que eu quero atender quando eu estiver formada...".

A universidade carrega a responsabilidade de passar essa formação diferenciada ao aluno, agregando fatores como aprendizado teórico, psicológico e prático, contribuindo para um profissional transformador e que atenda aos requisitos básicos para o serviço particular e público $^{17}$.

Dessa forma é responsabilidade da escola e do professor saber direcionar o processo de ensino aprendizagem na formação profissional em Odontologia de forma humanizada e ética. O mesmo deve buscar uma diversidade de cenários e casos clínicos para que seja possível enriquecer as experiências e o conteúdo das práticas aprendidas pelos alunos ${ }^{18}$. No que se refere ao estudante, futuros profissionais devem buscar uma consciên- 
cia crítica e reflexiva acerca da profissão e das posturas que deverão desempenhar.

\section{CONSIDERAÇÕES FINAIS}

O contato do discente de Odontologia com a clínica escola é uma experiência na qual o mesmo é requisitado a desenvolver o controle emocional, embasamento teórico, postura profissional diante do paciente e estratégias psicológicas para estabelecer o vínculo com o paciente, sob supervisão e auxílio dos professores.

Desse modo, se estabelece entre os alunos uma preocupação com o comportamento diante do primeiro contato com a clínica escola, gerando sentimentos como ansiedade, medo e insegurança. Entretanto, a função do docente é de tranquilizar o aluno evidenciando a ele que o conhecimento prático é estabelecido com a experiência adquirida ao decorrer das práticas clínicas.

Os docentes devem transpor a barreira do tecnicismo, valorizando a humanização na Odontologia, formando um profissional transformador, fazendo grande diferencial na saúde do seu paciente, e, consequentemente no mercado de trabalho. É válido ressaltar a importância de aliar o conhecimento teórico ao prático, o que confere ao aluno maior segurança para realizar os procedimentos a ele confiados. Além disso, o conhecimento prático melhora a destreza manual desses alunos, enquanto que o teórico auxilia na formação de diagnósticos, no modo de se comportar frente ao paciente e na realização de procedimentos.

\section{ABSTRACT \\ Dental student's first contact with the clinic: experience report}

To form professionals, teachers, the institution and students share responsibilities as the learning process provides the capacity to learn, to build relationship, build teamwork, communication and develop activities ethically. Facing this, the present study has the purpose to know and to understand the expectations of the Dental students in his first contact with the school clinic. This is the narrative of a descriptive character situation and also to explore, having as source interview with a 4th semester student. From the student was possible to classify his description into a group divided into three phases starting with desires and expectations, difficulties and success, all the way through the practical clinic and theory about the same subject. Has been detected that the student of odontology in his first contact with the clinic school shows a mix of expectation to do the work and the anxiety due to insecurity caused by the lack of experience with the patient. At the same time, he is facing little theoretical knowledge because this is just the first clinical practice.

Descriptors: Dentistry. Dental Students. Dental Schools.

\section{REFERÊNCIAS}

1. Costa, AMDD, Costa, JRV, Costa, MD, Costa, RD, Botrel, TEA. Contribuição do perfil do aluno de graduação em Odontologia para a redefinição dos recursos usados pelo professor no processo ensino-aprendizagem. UNIMEP 2002; 14(1):1-5.

2. Fonsêca, GS; Rodrigues AÁAO. O Programa de Educação pelo Trabalho para Saúde (PETSaúde) como indutor de inovações pedagógicas: a experiência do curso de Odontologia da Universidade Estadual de Feira de Santana, Bahia. Rev ABENO 2011; 11(2):19-26.

3. Schwartz B. An innovative approach to teaching ethics and professionalism. JCan Dent Assoc 2009; 75(5):338-40.

4. Leão ATT, Dias, K. Avaliação dos serviços de saúde prestados por faculdades de odontologia: a visão do usuário. Rev Bras Odontol Saúde Coletiva 2001; 2(1):40-6.

5. Bispo NTB, Cecchin D, Zanette F, Grazziotin-Soares R. Aquisição de conhecimento de estudantes de odontologia da UPF durante a graduação: avaliação sob parâmetros do Enade. RFO 2012;17(3):273-9.

6. Masetto MT, Prado, AS. Processo de avaliação da aprendizagem em um curso de 
Odontologia. Rev ABENO 2004; 4(1): 48-56.

7. Meira AR. Bioética e vulnerabilidade: o médico e o paciente. Rev Assoc Med Bras 2004; 50(3):249-51.

8. Nóbrega LM, Bernardino IM, Barbosa KGN, Oliveira PAP, Lucas RSCC, D'Avila S. A experiência de estudantes de Odontologia com dilemas éticos. Rev ABENO 2015. 15(4):10-8.

9. Cardoso AC, Corralo DJ, Krahl M, Alves LP. O estimulo à prática da interdisciplinaridade e do multiprofissionalismo: a Extensão Universitária como uma estratégia para a educação interprofissional. Rev ABENO 2015;15(2):12-9.

10. Cristino OS. Clínicas Integradas antecipadas: limites e possibilidades. Rev ABENO 2005; $5(1): 12-8$.

11. Oliveira RG, Oliveira RG, Dias AL, Júnior AMLF, Porto FR, Hespanhol FL, Silva RHA, Ricardo DR. Problematização como método ativo de ensino-aprendizagem em um Curso de Odontologia. Rev ABENO 2015; 15(2):7481.

12. Wink M. Humanização da relação assistencial entre o estudante de odontologia da Universidade Tuiuti do Paraná e o paciente da clínica integrada. Universidade Tuiuti do Paraná, 2011.

13. Marchini L, Patrocínio MC, Rode SM. Plano de ensino de uma disciplina de "urgências e emergências em Odontologia". Pós-Grad Rev Fac Odontol São José dos Campos 2000; 3(1):105-12.

14. Possobon RF, Carrascoza KC, Moraes ABA, Costa JRAL. O Tratamento Odontológico como gerador de ansiedade. Psicol Estudo 2007; 12(3):609-16.

15. Delors J. Educação: um tesouro a descobrir. 6a ed. São Paulo: Cortez; Brasília: UNESCO; 2001.

16. Fernandes AMR, Fernandes APS, Nascimento RL. Utilização da tecnologia de agentes para um ambiente virtual de ensino/ aprendizagem em Periodontia. Rev ABENO 2005; 5(1):23-31.

17. Pelissari LD, Basting RT, Flório FM. Vivência da realidade: o rumo da saúde para a Odontologia. Rev ABENO 2005; 5(1):32-9.

18. Ferreira NP, Ferreira AP, Freire MCM. Mercado de trabalho na odontologia: contextualização e perspectivas. Rev Odontol UNESP 2013; 42(4): 304-9.

Correspondência para:

Sérgio Donha Yarid

e-mail: syarid@hotmail.com

Universidade Estadual do Sudoeste da Bahia

Departamento de Saúde - Curso de Odontologia

Rua José Moureira Sobrinho, S/N

Jequiezinho

45206-190 Jequié, BA 